\title{
Laparoscopic resection of two peritoneal loose bodies on the rectosigmoid colon
}

\section{Ken-ichi Honda ${ }^{1 *}$, Tomoko Nakagawa ${ }^{1}$, Yasushi Kurihara ${ }^{1}$, Koji Kajitani ${ }^{1}$, Tetsuji Ando', Masashige Tendo², Aki Takase ${ }^{3}$, Akihiro Hamuro ${ }^{3}$}

\author{
${ }^{1}$ Department of Obstetrics and Gynecology, Kashiwara Municipal Hospital, Japan \\ ${ }^{2}$ Department of Surgery, Kashiwara Municipal Hospital, Japan \\ ${ }^{3}$ Department of Obstetrics and Gynecology, Osaka City University Graduate School of Medicine, Japan
}

Received: 23 November 2017

Accepted: 30 December 2017

\section{*Correspondence:}

Dr. Ken-ichi Honda,

E-mail: kenhonda@med.osaka-cu.ac.jp

Copyright: (c) the author(s), publisher and licensee Medip Academy. This is an open-access article distributed under the terms of the Creative Commons Attribution Non-Commercial License, which permits unrestricted non-commercial use, distribution, and reproduction in any medium, provided the original work is properly cited.

\section{ABSTRACT}

Laparoscopic examination of a 77-year-old woman revealed two peritoneal loose bodies connected to fatty appendices on the rectosigmoid colon and resected at the stalks. The peritoneal loose bodies were found to be fatcontaining masses on preoperative magnetic resonance imaging, and postoperative pathological examination revealed fat degeneration tissue with or without fibrous outer layers.

Keywords: Fat degeneration, Fatty appendix, Laparoscopy, Peritoneal loose body

\section{INTRODUCTION}

As fat-containing masses in the pelvic cavity, mature cystic teratomas are most likely to be found by computed tomography and magnetic resonance imaging (MRI) in women. However, other types of masses should also be considered. A peritoneal loose body is a possible intrapelvic mass containing fat, but the fat content is not always rich. We encountered a patient with two peritoneal loose bodies that were found as fat-containing masses during a preoperative MRI. ${ }^{1}$

\section{CASE REPORT}

A 77-year-old woman (gravida 3 para 3) consulted with us for treatment of dysuria due to grade 3 pelvic organ prolapse. Vaginal hysterectomy with Le Fort vaginal closure was scheduled. Preoperative MRI revealed two intrapelvic masses containing lipid (Figure 1). Laparoscopic removal of the masses, which we suspected to be mature cystic teratomas, was scheduled during surgery.
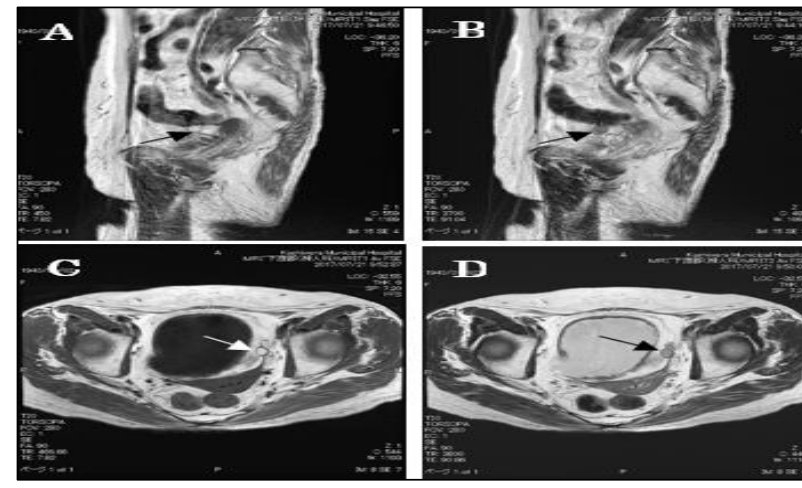

Figure 1: T1-weighted magnetic resonance imaging shows high-intensity signals (indicated with arrows) in the (A) sagittal and (C) horizontal sections of the pelvic cavity. T2WI shows relatively low signals (indicated with arrows) in sagittal (B) and horizontal (D) sections. 
Under laparoscopic examination, two spherical masses were observed with stalks connected to fatty appendices of the rectosigmoid colon (Figure 2).

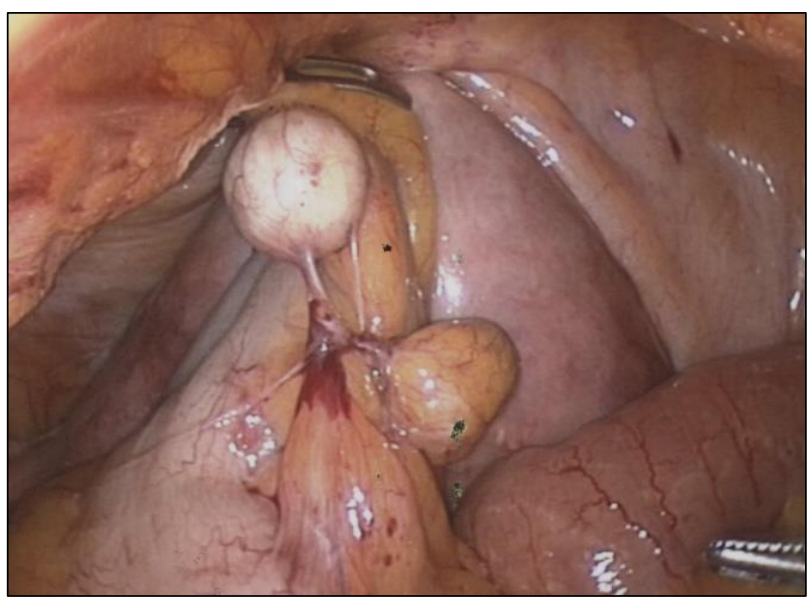

Figure 2: Two spherical masses with stalks (arrows) are connected to fatty appendices of the rectosigmoid colon.

The stalks were cut mechanically, and the bleeding points were treated with bipolar electrodes. Pathologic examination of frozen tissue sections showed fat degeneration products without malignant cells. After confirmation of haemostasis, vaginal hysterectomy and Le Fort closure of the vaginal wall were performed transvaginally.

The patient recovered smoothly with no problems of the digestive tract. The loose bodies had a smooth, whitish surface and fat degeneration in the core. Postoperative haematoxylin-eosin staining showed fat degeneration tissue in the centre and no cell atypia, with or without fibrous outer layers (Figure 3).

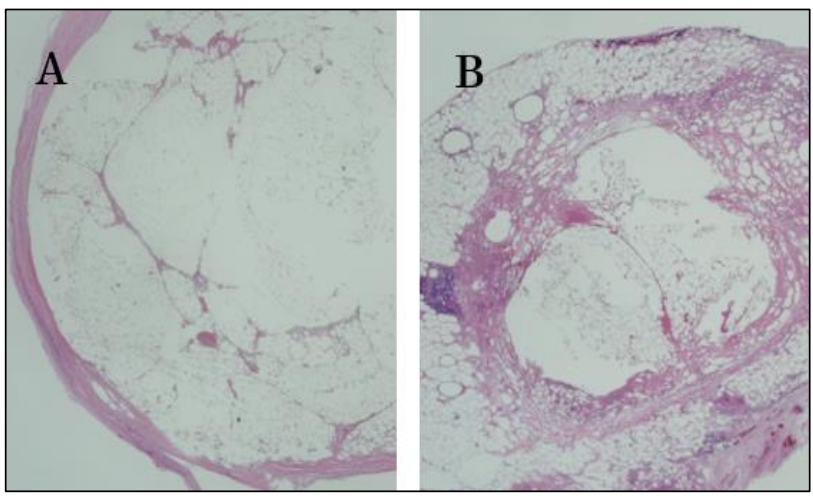

Figure 3. Postoperative hematoxylin-eosin staining shows fat degeneration, with (A) or without (B) outer layer fibrous layer.

\section{DISCUSSION}

Loose peritoneal bodies have been described as degeneration products of peritoneal pedicles around the colon. Peritoneal pedicles are small pouches of fat-filled peritoneum that protrude from the serosa of the cecum to the rectosigmoid colon.

They are 1 to $2 \mathrm{~cm}$ wide and 2 to $5 \mathrm{~cm}$ long, and approximately 50 to 100 in total can be seen on the colon. They are usually supplied via their stalk by one or two arterioles from the vasa recta of the colon and drained by a single tortuous venule. ${ }^{1,2}$

Histologically, a peritoneal loose body has a fibrous outer layer including a hyalinized fibrosclerotic and possible calcareous deposition or central fat necrosis., ${ }^{3,4}$ In the present case, a fat-containing signal was detected by MRI.

Recently, extraluminal structures like mesenteric fat tissue are focused for possible causes of inflammatory bowel disease. ${ }^{5}$

Total number of adipocytes in the mesentery is found to be increased in Crohn's disease patients and adiponectin mRNA and protein release are found to be upregulated in hypertrophied adipose tissue. Activated immune cells may be related to fat degeneration of peritoneal tissue.

In most cases, the peritoneal loose body is found incidentally, and no symptoms develop. In the present case, preoperative examination for pelvic organ prolapse revealed fat-containing masses in the pelvic cavity. Minimally invasive treatment using laparoscopy is considered appropriate for these masses.

\section{CONCLUSION}

Under laparoscopy, two peritoneal loose bodies were found and resected. Pathology revealed fat degeneration tissues with or without fibrous outer layers.

\section{Funding: No funding sources \\ Conflict of interest: None declared \\ Ethical approval: Not required}

\section{REFERENCES}

1. Ross JA. Vascular loops in the appendices epiploicae; their anatomy and surgical significance, with a review of the surgical pathology of appendices epiploicae. Br J Surg. 1950; 37:464-6.

2. Hapuarachchi KS, Courtney ED, Gergely S, Tang TY. Torsion of parietal-peritoneal fat mimicking acute appendicitis: a case report. J Med Case Reports. 2009;3:6980-2.

3. Zhang H, Ling YZ, Cui MM, Xia ZX, Feng Y, Chen CS. Giant peritoneal loose body in the pelvic cavity confirmed by laparoscopic exploration: a case report and review of the literature. World J Surg Oncol. 2015;13:118-22.

4. Matsubara K, Takakura Y, Urushihara T, Nishisaka $\mathrm{T}$, Itamoto T. Laparoscopic extraction of a giant 
peritoneal loose body: case report and review of literature. Int J Surg Case Rep. 2017;39:188-91.

5. Batra A, Stroh T, Siegmund B. Extraluminal factors contributing to inflammatory bowel disease. World J Gastroenterol 2011; 17: 572-77.
Cite this article as: Honda K, Nakagawa T, Kurihara Y, Kajitani K, Ando T, Tendo M, et al. Laparoscopic resection of two peritoneal loose bodies on the rectosigmoid colon. Int J Reprod Contracept Obstet Gynecol 2018;7:736-8. 